\title{
Dados geoquímicos e gamaespectrométricos na avaliação do potencial de corpos ígneos brasilianos para gerar concentrações de elementos terras raras do tipo ion adsorption clay (Terreno Apiaí-Guaxupé, estados de Minas Gerais e São Paulo, Brasil)
} Geochemical and gamma-spectrometry data on the evaluation of the potential of brasiliano igneous bodies to generate for rare earth elements ion adsorption clay concentration (Apiai-Guaxupé Terrain, Minas Gerais and São Paulo states, Brazil)

Ilio Rodarte Faria Júnior ${ }^{1}$, George Luiz Luvizzoto², Antonio Misson Godoy²

"Universidade Estadual Paulista “Júlio de Mesquita Filho" - UNESP, Instituto de Geociências e Ciências Exatas - IGCE, Programa de Pós-Graduação em Geociências e Meio Ambiente, Rua José Felício Castellano, 2.491, São Miguel, CEP 13506-405, Rio Claro, SP, BR (rdt.ilio@gmail.com)

2Universidade Estadual Paulista "Júlio de Mesquita Filho" - UNESP, Instituto de Geociências e Ciências Exatas - IGCE, Rio Claro, SP, BR (georgell@rc.unesp.br; mgodoy@rc.unesp.br)

Recebido em 8 de novembro de 2017; aceito em 19 de julho de 2018.

\begin{abstract}
Resumo
Os elementos terras raras apresentam crescente importância na economia mundial devido as suas aplicações na indústria de tecnologia, resultando em um crescente interesse pela prospecção de fontes minerais para esses elementos. Nesse âmbito, um tipo particular de mineralização conhecido na China se destaca por representar a principal fonte de elementos terras raras pesados (Eu a Lu) e ítrio (Y), menos comuns do que de elementos terras raras leves (La a Sm). Esse tipo de depósito, denominado ion adsorption clay, é composto de perfis de intemperismo desenvolvidos a partir de biotita e/ou muscovita sienogranitos, com a concentração exógena dos elementos terras raras originando-se pela adsorção desses elementos em argilominerais neoformados pelo processo intempérico. Características diversas afetam a gênese desses depósitos, onde a presença de minerais de elementos terras raras muito susceptíveis ao intemperismo e as características de desenvolvimento da alteração exógena são de grande importância para esse tipo de enriquecimento de elementos terras raras. O Terreno Apiaí-Guaxupé, onde foram selecionados corpos ígneos para a presente avaliação, é portador de uma diversidade de corpos ígneos, os quais foram afetados por processos de intemperismo cenozóicos, representando uma região com potencial prospectivo para esse tipo de depósito. Os corpos ígneos avaliados não apresentam informações descritivas sobre minerais (fluor)carbonáticos de elementos terras raras, muito susceptíveis ao intemperismo e importantes para a gênese desses depósitos de concentração exógena. Dessa forma, faz-se necessário o uso de informações químicas, descrições de minerais acessórios e de sobreposição de processos de alteração hidrotermal na busca de definir a possibilidade de formação dos minerais (fluor)carbonáticos de elementos terras raras. A investigação da potencialidade de enriquecimento de elementos terras raras do tipo ion adsorption clay para esse terreno partiu da compilação de informações publicadas de 16 corpos ígneos brasilianos sin-, tardi- e pós-orogênicos, abrangendo dados geológicos, químicos (228 amostras) e mineralógicos. A análise comparativa entre esses dados e os corpos geradores dessas mineralizações de elementos terras raras do tipo ion adsorption clay apontou similaridades de cinco granitoides com granitos chineses que originaram essas concentrações. Informações de aerogamaespectrometria corroboram a presença de perfis de intemperismo nesses cinco corpos, indicando potencialidade para avanço das pesquisas desse modelo de mineralização de elementos terras raras.
\end{abstract}

Palavras-chave: Elementos terras raras; Intemperismo; Concentração exógena; Granitoides; Adsorção.

Abstract

The rare earth elements are of increasing importance in the world economy, mainly due to their applications in the technology industry, which leads to the interest in prospecting mineral sources for these elements. In this context, a particular model of mineralization known in China stands out as the main source of heavy rare earth elements (Eu to Lu) and yttrium (Y), less common than light rare earth elements ( $\mathrm{La}$ to $\mathrm{Sm}$ ). This deposit type, called ion adsorption clay, consists of weathering 
profiles developed from biotite and/or muscovite granites, where the exogenous concentration of rare earth elements is given by the adsorption of these elements by neoformed kaolinitic clays by the weathering process. Several characteristics affect the genesis of these mineralizations, where the presence of rare earth elements minerals very susceptible to weathering and developmental characteristics of the exogenous alteration are of great importance for this type of rare earth elements enrichment. The Apiaí-Guaxupe Terrain, with a diversity of igneous bodies and Cenozoic weathering process, is an example of area with prospective potential to this deposit type. There are no descriptive information about rare earth elements (fluor)carbonate minerals, very susceptible to weathering and primordial to the genesis of these deposits, in these igneous bodies. Thus, the use of chemical informations and descriptions over accessory minerals and hydrothermal alteration to define the possibility of rare earth elements formation is necessary. In this work, the investigation of the potential enrichment of ion adsorption clay-type rare earth elements for this terrain was based on the use of published information of 16 syn-, tardi- and post-orogenic, Brasiliano igneous bodies,encompassing geologic, chemical (228 samples) and mineralogical data. The comparative analysis among this data and the bodies that generate these ion adsorption clay-type rare earth elements mineralization show similarities of five granitoids with Chinese granites that gave rise to these concentrations. Gamma-spectrometry data corroborate the presence of weathering profiles in these five bodies, indicating potential to advancing the research on this model of rare earth elements mineralization.

Keywords: Rare earth elements; Weathering; Exogenous concentration; Granitoids; Adsorption.

\section{INTRODUÇÃO}

Os depósitos de elementos terras raras (ETR) e ítrio (Y) do tipo ion adsorption clay (IAC) explotados no sul da China mostram grande importância mundial por serem as únicas fontes economicamente viáveis de elementos terras raras pesados (ETRP) (Bao e Zhao, 2008; Sanematsu e Watanabe, 2016). A viabilização desse tipo de depósito, cujos teores totais de ETR são inferiores a $0,3 \%$, dá-se pelos menores custos de lavra do saprolito granítico, pela facilidade de extração dos ETR adsorvidos em argilominerais neoformados e pelo conteúdo irrelevante de elementos radioativos ( $\mathrm{U}$ e $\mathrm{Th}$ ) associados aos minerais de minério (Bao e Zhao, 2008).

Ainda que diversos trabalhos tenham sido conduzidos nesse sentido, não há um consenso sobre todos os condicionantes de gênese dos granitos que originam as ocorrências de ETR do tipo IAC. Então, entende-se que para estabelecer bases prospectivas, os litotipos de maior interesse são biotita e/ou muscovita sienogranitos metaluminosos a peraluminosos (Sanematsu e Watanabe, 2016). Ainda assim, essas concentrações de ETR do tipo IAC também já foram reconhecidas em tufos vulcânicos, aplitos, lamprófiros e sienitos (Bao e Zhao, 2008; Harmer e Nex, 2016).

$O$ processo de alteração hidrotermal, especialmente a greisenização, é responsável pela gênese dos minerais (fluor) carbonáticos de ETR, além de promover o enriquecimento de ETRP e Y (Ishihara et al., 2008; Watanabe et al., 2017). Esses minerais podem ser encontrados preenchendo planos de junta diversos na rocha ou sendo originados a partir da alteração de titanita e allanita (Watanabe et al., 2017). Ao final, a gênese dos depósitos do tipo IAC é conduzida pela atuação de processo de intemperismo tropical sobre esses granitos, o qual é responsável pela liberação dos ETR de sua mineralogia original, pela mobilidade e pelo enriquecimento desses elementos por adsorção em argilominerais neoformados (Sanematsu e Watanabe, 2016).
No Brasil, a abordagem dessas concentrações exógenas de ETR em granitos está restrita a corpos da Província Estanífera de Goiás (Marini et al., 1992). Aplicou-se aqui, então, uma avaliação comparativa dos corpos ígneos do Terreno Apiaí-Guaxupé (Campos Neto, 2000; Janasi et al., 2009), nos estados de Minas Gerais e São Paulo, com aqueles granitos geradores de mineralizações de ETR do tipo IAC no Sudeste Asiático, visando, com isso, à prospecção de litologias com características promissoras para gênese desse tipo de concentração exógena de ETR. Para isso, foi feita a compilação de informações geológicas, mineralógicas e químicas (Documento suplementar) abordando 16 corpos ígneos situados nos domínios do Terreno Apiaí-Guaxupé dentro da Folha Geológica SF.23 (Rio de Janeiro, 1:1.000.000) (RADAMBRASIL, 1983).

Os dados levantados abrangem corpos ígneos sin-, tardi- e pós-tectônicos, com aspectos geológicos, litológicos e químicos distintos. Uma vez que esses corpos dispõem de limitada caracterização de petrografia de alta resolução (MEV e/ou Microssonda) de minerais portadores de ETR, assim como de processos de alteração magmática/hidrotermal, foi dado maior atenção às características químicas na busca de definir a presença de condicionantes que possam gerar aspectos de interesse para gênese do modelo de concentração de ETR do tipo IAC, especialmente os minerais (fluor)carbonáticos de ETR. A avaliação comparativa desses dados e a adição de informações aerogamaespectrométricas permitiram identificar corpos graníticos com aspectos similares àqueles que originaram as jazidas chinesas de concentração exógena de ETR. Esses resultados abrem um potencial prospectivo para ETR em uma região do Brasil com avançada maturidade dos conhecimentos geológicos, mas que, até então, não teve abordagem da potencialidade para o enriquecimento desses elementos por adsorção em argilominerais neoformados. 


\section{MATERIAIS E MÉTODOS}

\section{Aspectos geológicos e geomorfológicos}

Os corpos ígneos brasilianos sin-, tardi- e pós-orogênicos dos domínios Socorro-Guaxupé e Apiaí-São Roque (Terreno Apiaí-Guaxupé) (Figura 1) pertencem às suítes calcioalcalinas, calcioalcalinas de alto potássio $(\mathrm{K})$ a alcalinas e tipo-A anorogênicas (Wernick e Galembeck, 1986; Wernick, 2000; Janasi et al., 2009; Heilbron et al., 2004; Tupinambá et al., 2012). Esses domínios são resultantes da orogênese neoproterozoica/cambriana, que culminou na aglutinação do paleocontinente Gondwana (Brito Neves e Fuck, 2014).

Os domínios Socorro-Guaxupé e Apiaí-São Roque são representantes da margem ativa da Placa Paranapanema na Orogênese Brasiliana (Janasi et al., 2009). O primeiro domínio é marcado pela subducção Criogeniana da Placa São Francisco em direção a SW, enquanto o segundo foi submetido a uma subducção Ediacarana do Terreno Curitiba em direção a NW (Campos Neto, 2000; Janasi et al., 2009).

O Terreno Guaxupé, sul da Faixa Brasília, apresenta trend $\mathrm{N}-\mathrm{S}$ e se estrutura na forma de nappes cavalgando de

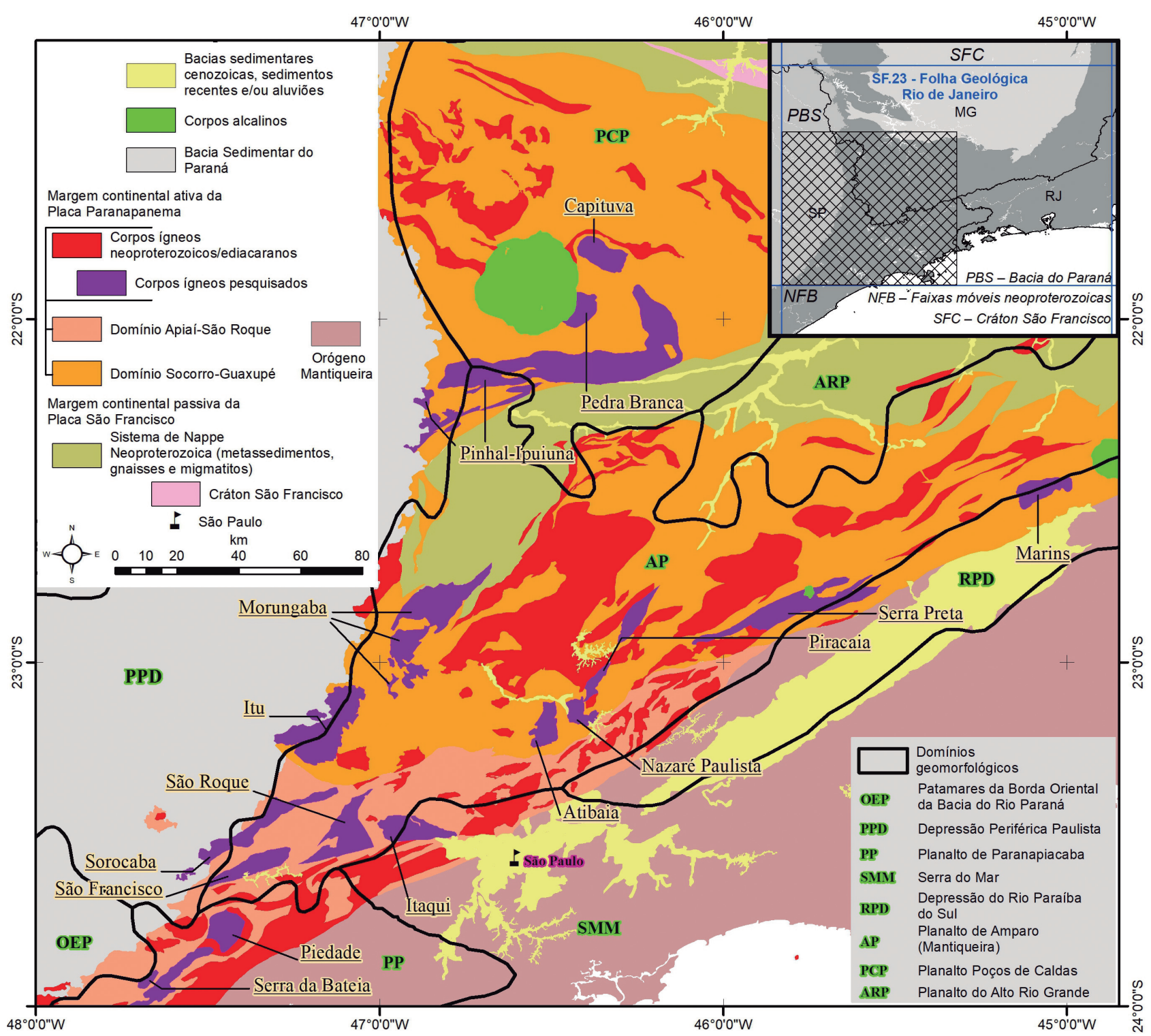

Figura 1. Domínios geológicos e geomorfológicos da porção sudoeste da Folha SF.23 (Rio de Janeiro), com destaque para os corpos ígneos abordados na análise comparativa. 
W para E, com grau metamórfico variando de fácies granulitos a xisto verde de W para E (Campos Neto et al., 2004). O Terreno Apiaí, parte do sistema orogênico Mantiqueira, mostra trend NE-SW e é formado por cinturões de empurrão e dobramento em sistema transpressivo de evolução diacrônica (Heilbron et al., 2004; Janasi et al., 2009).

A Nappe Socorro-Guaxupé apresenta granulitos e rochas diatexíticas e metatexíticas, os quais são seguidos por intrusões ígneas sin-orogênicas resultantes de reciclagem crustal e coincidentes com o pico metamórfico (625 a $610 \mathrm{Ma)} \mathrm{(Töpfner,} \mathrm{1996;} \mathrm{Campos} \mathrm{Neto,} \mathrm{2000;} \mathrm{Janasi,}$ 2002; Martins et al., 2009).

Esse magmatismo se subdivide nas suítes mangerítica (ca. 630-625 Ma), originada na fusão de granulitos; calcioalcalina (de alto K) (ca. 625-620 Ma), gerada de ortognaisses da crosta média (quebra da biotita); e nos granitos anatéticos (ca. $625 \mathrm{Ma}$ ), originados de paragnaisses (quebra da muscovita) (Artur, 1988; Töpfner, 1996; Janasi, 1999, 2002).

As rochas mangeríticas mostram assinatura de manto empobrecido, enquanto as rochas calcioalcalinas têm origem em fonte crustal (Janasi, 2002) ou mantélica seguida de interação com a crosta continental (Janasi e Ulbrich, 1991). As intrusões magmáticas nesse domínio se encerram com os maciços sieníticos pós-cinemáticos Capituva e Pedra Branca (Janasi, 1992; Töpfner, 1996; Carvalho et al., 2014), cujos magmas parentais são originados de porções enriquecidas do manto litosférico subcontinental (Janasi, 1992; Carvalho et al., 2014).

O Domínio Apiaí-São Roque mostra baixo grau metamórfico, sendo constituído por uma sequência metavulcanossedimentar, rochas metacarbonáticas e corpos intrusivos (Heilbron et al., 2004). Apresenta intrusões de granitos sin-orogênicos calcioalcalinos (de alto K), entre 615 e $605 \mathrm{Ma}$ (Prazeres Filho et al., 2003), e tardi-orogênicos (600 Ma) (Leite et al., 2007). Os magmas dos corpos sin-orogênicos se originaram em manto enriquecido, seguido de interação com a crosta (Janasi e Vlach, 1997). Os magmas tardi-orogênicos foram gerados por anatexia da crosta média e contaminados pela crosta superior durante sua ascensão (Leite et al., 2007).

A Província Granítica Itu, mais jovem do domínio, contem granitos rapakivis, calcioalcalino potássicos e tipo-A da série aluminosa (Galembeck, 1997; Wernick, 2000; Janasi et al., 2009). A fase magmática principal dessa província gerou os litotipos monzo/sienograníticos (Godoy et al., 2010), com seus corpos encontrados intrudidos nas proximidades do que hoje representa a borda da Bacia do Paraná, presentes nos dois domínios descritos (Apiaí-São Roque e Socorro-Guaxupé) (Janasi et al., 2009).

A Província Itu foi composta por magmas de origem mantélica com interação de outras fontes distintas (Janasi et al., 2009). Seus litotipos mais diferenciados, contendo muscovita e fluorita, podem portar mineralizações metálicas derivadas de exo/endo greisenização (Wernick, 2000), apresentando cassiterita, wolframita, topázio e sulfetos (Vlach et al., 1991; Pereira et al., 2001).

Os corpos ígneos investigados encontram-se, majoritariamente, nas unidades geomorfológicas Planaltos de Paranapiacaba, de Amparo e de Poços de Caldas (RADAMBRASIL, 1983). O relevo predominante nessas unidades se associa ao desenvolvimento de pronunciado intemperismo químico afetando o substrato rochoso, resultando em perfis intempéricos de variadas profundidades, cujas feições características são colinas com topo aplanado ou arredondado e drenagens entalhadas segundo os principais traços estruturais (RADAMBRASIL, 1983). Essas condições condizem com a instalação e a preservação, ainda que parcial, de perfis de intemperismo, afetando, entre outros, os corpos ígneos abordados.

\section{Depósitos de elementos terras raras do tipo ion adsorption clay}

Poucos minerais mostram importância econômica para explotação dos ETR (Linnen et al., 2014). A bastnasita é responsável pela produção de 70 a $80 \%$ dos elementos terras raras leves (ETRL), complementada pela monazita, enquanto os ETRP e Y são, quase exclusivamente, oriundos dos depósitos lateríticos adsorvidos em argilas, originados a partir de corpos graníticos (Mariano e Mariano, 2012; Linnen et al., 2014).

As características dos corpos graníticos mineralizados no Sudeste Asiático podem ser utilizadas como base para a prospecção de granitos similares e, então, com potencialidade para a gênese de enriquecimento de ETR do tipo IAC. Esses exemplares chineses são, em sua maioria, granitos calcioalcalinos, metaluminosos a fracamente peraluminosos (alumina saturation index - ASI $\sim 1,1$ ), com teores de $\mathrm{SiO}_{2}$ superiores a $70 \%$, então muito diferenciados (Sanematsu e Watanabe, 2016). Esses corpos graníticos são portadores de considerável conteúdo de ETR, comumente superiores a $100 \mathrm{ppm}$, sendo a titanita e a allanita importantes detentores desses metais no momento da cristalização magmática (Watanabe et al., 2017). Esses tipos graníticos instalam-se em momento e ambiente tectônico compatíveis com a superposição de processos de alteração magmática e/ou hidrotermal tardi- e/ou pós-magmáticos (Sanematsu e Watanabe, 2016; Watanabe et al., 2017).

Os minerais de ETR susceptíveis ao intemperismo, como carbonatos e fluorcarbonatos, são de alta importância para a gênese desse tipo de mineralização exógena, já que garantem a fácil liberação desses elementos quando submetidos ao processo intempérico (Bao e Zhao, 2008; Sanematsu e Watanabe, 2016). Nesse sentido, quando granitos portadores de titanita e allanita são afetados por greisenização, esses minerais silicáticos podem ser 
substituídos, parcial ou totalmente, por (fluor)carbonatos de ETR, enquanto essa alteração também promove o enriquecimento de ETRP e Y, menos comuns do que os ETRL (Watanabe et al., 2017). Destaca-se, ainda, a importância do baixo conteúdo de $\mathrm{P}_{2} \mathrm{O}_{5}$, resultando em diminuta presença de fosfatos de ETR, os quais são resistentes ao intemperismo e dificultam a liberação desses elementos no perfil de intemperismo (Sanematsu et al., 2015).

Os perfis portadores de mineralização de ETR do tipo IAC se subdividem em horizontes intempéricos marcados pela lixiviação desses elementos nas porções superiores do perfil e acúmulo no saprolito (Wu et al., 1990; Bao e Zhao, 2008; Sanematsu et al., 2013). Atingidas as condições propícias, os ETR mobilizados ao longo do perfil podem ser enriquecidos ao serem adsorvidos por argilominerais neoformados (Guangzhi, 1996), onde a liberação desses elementos das mineralogias originais, o transporte ao longo do perfil e as condições geoquímicas para adsorção podem promover, quando comparados à rocha, mudanças na diferenciação entre ETRL e ETRP no horizonte enriquecido (Nesbitt, 1979; Bao e Zhao, 2008; Sanematsu et al., 2013). Como produto final, os depósitos exógenos resultantes são compostos por mais de $500 \mathrm{ppm}$ de ETR adsorvidos em argilas neoformadas no horizonte saprolítico (Bao e Zhao, 2008; Sanematsu et al., 2015).

\section{Corpos ígneos avaliados}

Foram obtidas informações de literatura de 16 corpos ígneos (Tabela 1), somando 228 resultados geoquímicos que abrangem os conteúdos de óxidos maiores $\left(\mathrm{SiO}_{2}, \mathrm{TiO}\right.$,
$\mathrm{Al}_{2} \mathrm{O}_{3}, \mathrm{Fe}_{2} \mathrm{O}_{3}, \mathrm{MnO}, \mathrm{MgO}, \mathrm{CaO}, \mathrm{Na}_{2} \mathrm{O}, \mathrm{K}_{2} \mathrm{O}$ e $\mathrm{P}_{2} \mathrm{O}_{5}$ ) e ETR (Documento suplementar), cujas análises contemplam a rocha total não intemperizada. Foram tomadas, também, as descrições sobre as litologias que compõem esses corpos, indicativos de processos de alteração e, quando disponíveis, dados sobre mineralogias portadoras de ETR.

Os dados compilados são provenientes de fontes bibliográficas diversas, as quais refletem pesquisas desenvolvidas em momentos distintos, resultando em uma heterogeneidade de analitos abrangidos por esse total de resultados químicos. Por esse motivo, foram aplicadas, nas análises gráficas comparativas, as amostras com, no máximo, 3 dos ETR não analisados ou resultados com $\Sigma E T R$ de, no mínimo, $250 \mathrm{ppm}$. Buscou-se, com isso, tratar resultados mais completos, que pudessem refletir os conteúdos totais de ETR mais próximos ao real, ou seja, com caracterização química de todos esses elementos, e também com um conteúdo mínimo que permitisse atingir teores significativos após um possível enriquecimento exógeno.

Os corpos ígneos pesquisados apresentam diversos tipos litológicos, com uma ampla variação mineralógica e geoquímica. Esses corpos também apresentam diferentes momentos tectônicos de instalação e fontes magmáticas variando entre mantélicas e crustais, permitindo abordar uma ampla gama de corpos geológicos e determinar aqueles que melhor se encaixam entre as características mais promissoras às concentrações de ETR do tipo IAC. Optou-se aqui pela utilização da base geológica compilada por Leite et al. (2004), o que se deve à abrangência de suas informações e à disponibilização em arquivo digital.

Tabela 1. Corpos ígneos abordados na análise comparativa do presente trabalho, litotipos predominantes, idades e fontes de compilação de dados químicos.

\begin{tabular}{lcc}
\hline Corpo ígneo & Litotipos predominantes & $\begin{array}{c}\text { Idades máximas compiladas } \\
\text { por Leite et al. (2004) (em Ma) }\end{array}$ \\
\hline Serra Preta & Monzo e sienogranitos (Santoro, 1998) & 630 \\
Itaqui & Granodioritos, monzonitos e monzogranitos (Ferreira, 1996) & 630 \\
Pinhal-Ipuiuna & Monzo e sienogranitos, quartzo monzonitos, sienitos (Haddad, 1995) & 624 \\
Nazaré Paulista & Monzo e sienogranitos (Martins, 2005) & 623 \\
Morungaba & Quartzo monzonito, monzo e sienogranitos (Janasi et al., 2009) & 620 \\
Pedra Branca & Sienitos e quartzo-sienitos (Carvalho e Janasi, 2012) & 613 \\
Capituva & Sienitos e quartzo-sienitos (Janasi, 1992) & 610 \\
Marins & Monzo e sienogranitos (Duffles et al., 2013) & 612 \\
Sorocaba & Monzo e sienogranitos (Godoy, 1989) & 610 \\
Piedade & Monzo e sienogranitos (Leite et al., 2006) & 605 \\
Atibaia & Sienogranitos (Melhem, 1995) & 590 \\
São Roque & Monzo e sienogranitos (Godoy et al., 2010) & 586 \\
Itu & Monzo e sienogranitos (Galembeck, 1997) & 582 \\
Piracaia & Monzodioritos e monzonitos (Ragatky, 1998; Janasi et al., 2009) & 577 \\
Serra da Bateia & Sienogranitos (Leite et al., 2007) & 564 \\
São Francisco & Monzo e sienogranitos (Godoy, 1989) & 560 \\
\hline
\end{tabular}


A caracterização da presença de minerais (fluor)carbonáticos de ETR nessas rochas, os quais são muito importantes para gênese desses depósitos exógenos (Bao e Zhao, 2008; Sanematsu e Watanabe, 2016), exige o uso de petrografia de alta resolução (microscópio eletrônico de varredura MEV ou microssonda), o que dificulta a obtenção desse tipo de informação apenas por meio da literatura. Assim, a compilação e a aplicação de aspectos químicos dos corpos graníticos e descrições de alteração magmática e/ou hidrotermal se firmam como o método prospectivo mais abrangente para utilização dos dados disponíveis em literatura, buscando, com isso, características que possam corroborar a presença, nos corpos ígneos, desses minerais, que são de maior interesse para esse modelo de mineralização.

\section{Aerogamaespectrometria}

As mineralizações de ETR do tipo IAC são encontradas em perfis de intemperismo tipicamente tropical, onde se desenvolve espesso horizonte saprolítico, gerando, assim, condições para que haja a possibilidade de adsorção desses elementos em argilominerais neoformados (Wu et al., 1990; Bao e Zhao, 2008; Sanematsu et al., 2013). Após liberação desses elementos de seus minerais originais, e consequente mobilidade no meio exógeno (Nesbitt, 1979), diversos condicionantes durante o processo de intemperismo influem na capacidade da adsorção dos ETR nessas argilas. Dentre os fatores que governam a adsorção, pode-se citar as condições de $\mathrm{pH}$, cujo intervalo mais favorável para adsorção se coloca entre 5 e 6; o tamanho dos argilominerais, mais propício em cristais de menor tamanho; e a força iônica dos ETR na solução de transporte (Guangzhi, 1996). Devido à diversidade de fatores que implicam na adsorção dos ETR em argilominerais, uma vez definidos os corpos que satisfazem as características químicas e litológicas para prospecção desse tipo de enriquecimento exógeno, é preciso prosseguir com a identificação da presença de perfis de intemperismo com espessos saprolitos, tipicamente desenvolvidos em ambiente tropical (Sanematsu e Watanabe, 2016).

Os dados de aerogamaespectrometria são amplamente aplicados na prospecção e na identificação de perfis lateríticos (Wilford et al., 1997). Quando afetados pelo intemperismo tropical, o K mostra maiores condições de ser lixiviado do que o tório (Th). Consequentemente, um cenário retratado pelo enriquecimento do Th em relação ao K pode ser indicativo da presença de perfis lateríticos preservados da ação erosiva (Wilford et al., 1997; Ulbrich et al., 2009), especialmente nos domínios de corpos graníticos portadores de feldspato potássico, que são rochas com alto conteúdo de K em comparação ao Th.

Após a avaliação comparativa entre os dados químicos dos corpos ígneos aqui abordados e aqueles granitos geradores de mineralizações exógenas de ETR no Sudeste Asiático, foram aplicadas as informações de aerogamaespectrometria a esses corpos selecionados para, com base na relação $\mathrm{Th} / \mathrm{K}$, buscar indícios da presença de perfis intempéricos preservados em seus domínios. Os dados aerogeofísicos utilizados são os arquivos que se encontram disponibilizados pela Companhia de Pesquisa e Recursos Minerais do Brasil (CPRM) em mídia digital, nesse caso, para o levantamento 1.039 (São Paulo - Rio de Janeiro [Área SP], 1978).

\section{RESULTADOS E DISCUSSÃO}

Ainda que se tenha uma ampla variedade de fatores que possam interferir na gênese dos depósitos exógenos de ETR, um levantamento prospectivo se embasa na somatória de critérios favoráveis que estabeleçam corpos com maior potencialidade para sustentar avaliações in loco. Nesse âmbito, os corpos graníticos chineses dotados de mineralizações de ETR do tipo IAC apresentam as características litológicas, químicas, mineralógicas e de perfis de intemperismo a serem tomadas como base para aplicação em análises comparativas visando à prospecção de corpos similares no Terreno Apiaí-Guaxupé.

\section{Aspectos químicos}

Uma série de amostras compiladas apresentou altos conteúdos de $\mathrm{SiO}_{2}$ e $\mathrm{K}_{2} \mathrm{O}$, os quais são compatíveis com o grau de evolução magmática dos granitos geradores desse modelo de concentração exógena (Figura 2), como aqueles exemplares de fácies graníticas dos corpos Itu, São Francisco, Sorocaba, Marins, Serra Preta, Morungaba, Atibaia, Pinhal-Ipuiuna e Piedade. Na figura 2, a dispersão de amostras de um mesmo corpo sugere variações na potencialidade de acordo com as diferentes fácies graníticas dos corpos avaliados, o que se repete mesmo dentro dos corpos selecionados segundo esse critério.

Os corpos levantados apresentam, majoritariamente, ASI entre 1,1 e 1,5 (rochas peraluminosas). Exceções são identificadas nos corpos sieníticos e em fácies dos corpos graníticos Itu, São Francisco, Sorocaba, Itaqui, Morungaba e Serra da Bateia, com rochas próximas à transição entre metaluminosas e peraluminosas (ASI entre 1 e 1,1), os quais dispõem de $\Sigma$ ETR superior a 100 ppm, conteúdo mínimo dos corpos geradores de concentrações do tipo IAC (Bao e Zhao, 2008; Sanematsu e Watanabe, 2016). Os corpos destacados neste parágrafo mostram relação inversa entre os valores de ASI e o $\mathrm{SiO}_{2}$, resultando em fácies graníticas evoluídas e com valores de ASI próximos àqueles dos granitos geradores das concentrações de ETR. Tal aspecto reforça a diversificação de potencialidade dentro de um mesmo corpo, dado que fácies com ASI próximo a 1 e com essa diferenciação magmática tendem a apresentar expressivo conteúdo de ETR em titanitas e allanitas, as quais, por 
alteração hidrotermal, podem gerar os minerais de interesse para desenvolvimento desse modelo de mineralização aqui tratado (Watanabe et al., 2017).

O conjunto total de dados (Documento suplementar) mostrou baixa correlação do ASI com outros parâmetros, resultando nos coeficientes de Pearson de $0,368 \mathrm{com} \mathrm{SiO}_{2}$, $-0,062 \mathrm{com} \mathrm{La}_{\mathrm{N}} / \mathrm{Yb}_{\mathrm{N}} \mathrm{e}-0,618 \mathrm{com}$ a $\Sigma$ ETR. Isso impossibilita estabelecer parâmetros comparativos e conexões que auxiliem na pesquisa de litotipos potenciais ao modelo estudado, diferentemente do que notou Sanematsu e Watanabe (2016) nas amostras compiladas por eles para os corpos que originam essas concentrações exógenas.

Junto aos exemplares com maior diferenciação magmática, indicados na Figura 2, a Figura 3 situa, também, os maciços Nazaré Paulista e São Roque no campo de potencialidade para concentrações de ETRL do tipo IAC, onde se faz necessária a avaliação da mineralogia portadora desses elementos para aferir essa potencialidade. Observando o conjunto total de dados da Figura 3, nota-se, para a faixa de $\mathrm{SiO}_{2}$ superior a $70 \%$, uma grande quantidade de resultados com conteúdo total de ETR superiores aos daqueles granitos geradores de depósitos do tipo IAC ricos em ETRP.
Entre os resultados compilados, apenas uma amostra do Granito São Francisco foi compatível com o campo da relação $\mathrm{La}_{\mathrm{N}} / \mathrm{Yb}_{\mathrm{N}}$ de geração de concentrações de exógenas de ETRP (Figura 4). Já os maciços Piedade, Marins e Sorocaba plotam amostras no campo daqueles potenciais geradores de depósitos exógenos de ETRL, com relações $\mathrm{La}_{\mathrm{N}} / \mathrm{Yb}_{\mathrm{N}}$ variando entre 20 e 70 . Cabe destacar que, nesse quesito, os maciços Nazaré Paulista e São Roque não se repetiram aqui como potenciais às concentrações desses elementos leves.

Os maciços Itaqui e Serra Preta mostram fácies graníticas com $\Sigma E T R$ superior a $300 \mathrm{ppm}$ e alto enriquecimento relativo de ETRL (Figuras 3 e 4). Esses aspectos parecem ser condizentes com a evolução típica do fracionamento magmático, resultando em minerais acessórios de ETR resistentes ao intemperismo, fazendo com que essas fácies sejam pouco potenciais à gênese de depósitos do tipo IAC. Essa observação fundamenta-se nas descrições de Watanabe et al. (2017) para esse modelo de depósito, onde o enriquecimento relativo de ETRP se originaria do processo de alteração hidrotermal, responsável, também, pela formação de minerais de ETR susceptíveis ao intemperismo.

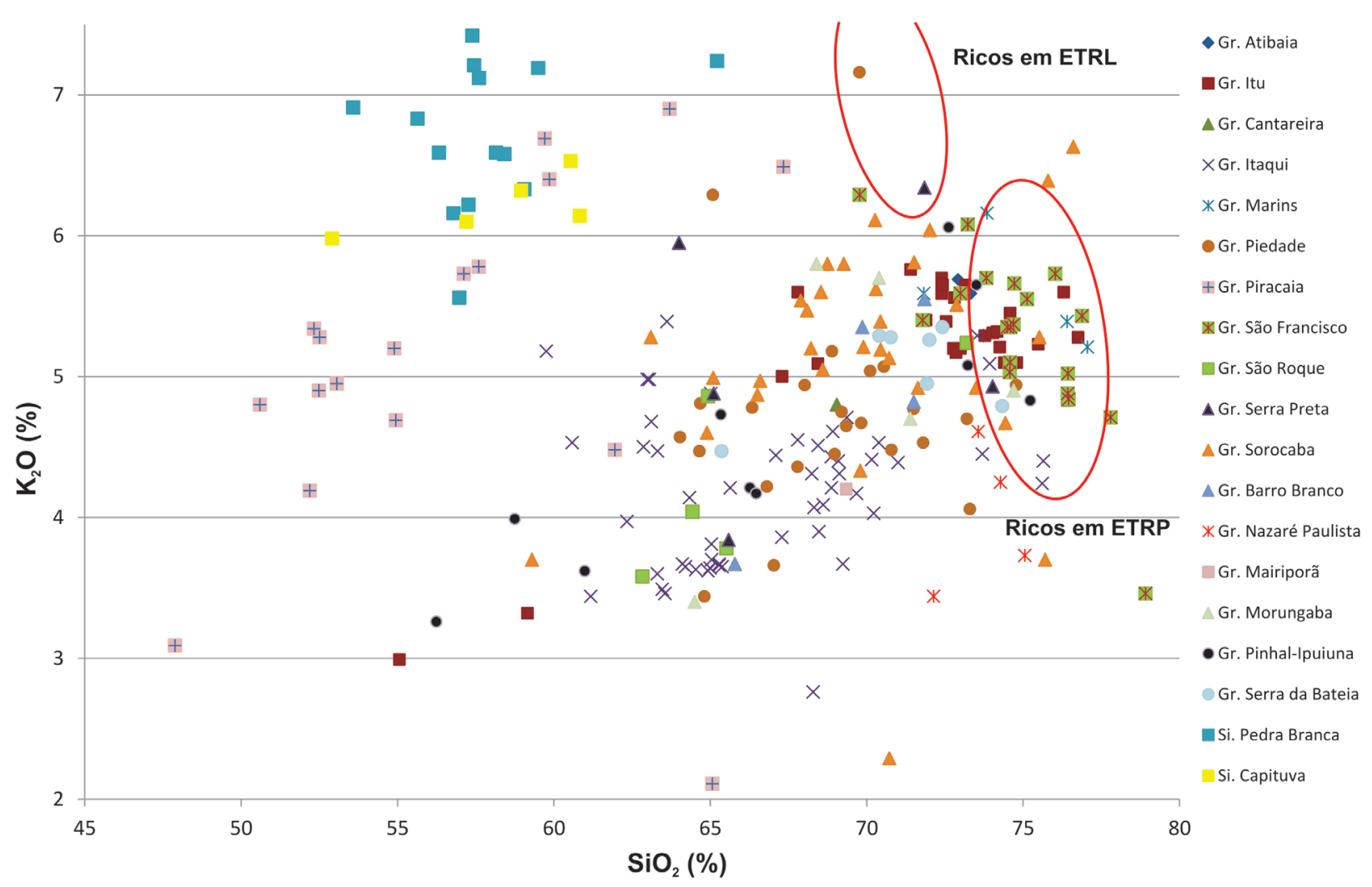

ETRL: elementos terras raras leves; ETRP: elementos terras raras pesados. Fonte: Sanematsu e Watanabe (2016).

Figura 2. Relação do conteúdo de sílica $\left(\mathrm{SiO}_{2}\right)$ e potássio $\left(\mathrm{K}_{2} \mathrm{O}\right)$ nos corpos ígneos estudados e comparação com os campos delimitados por resultados químicos dos granitos geradores dos depósitos chineses de elementos terras raras tipo ion adsorption clay. 


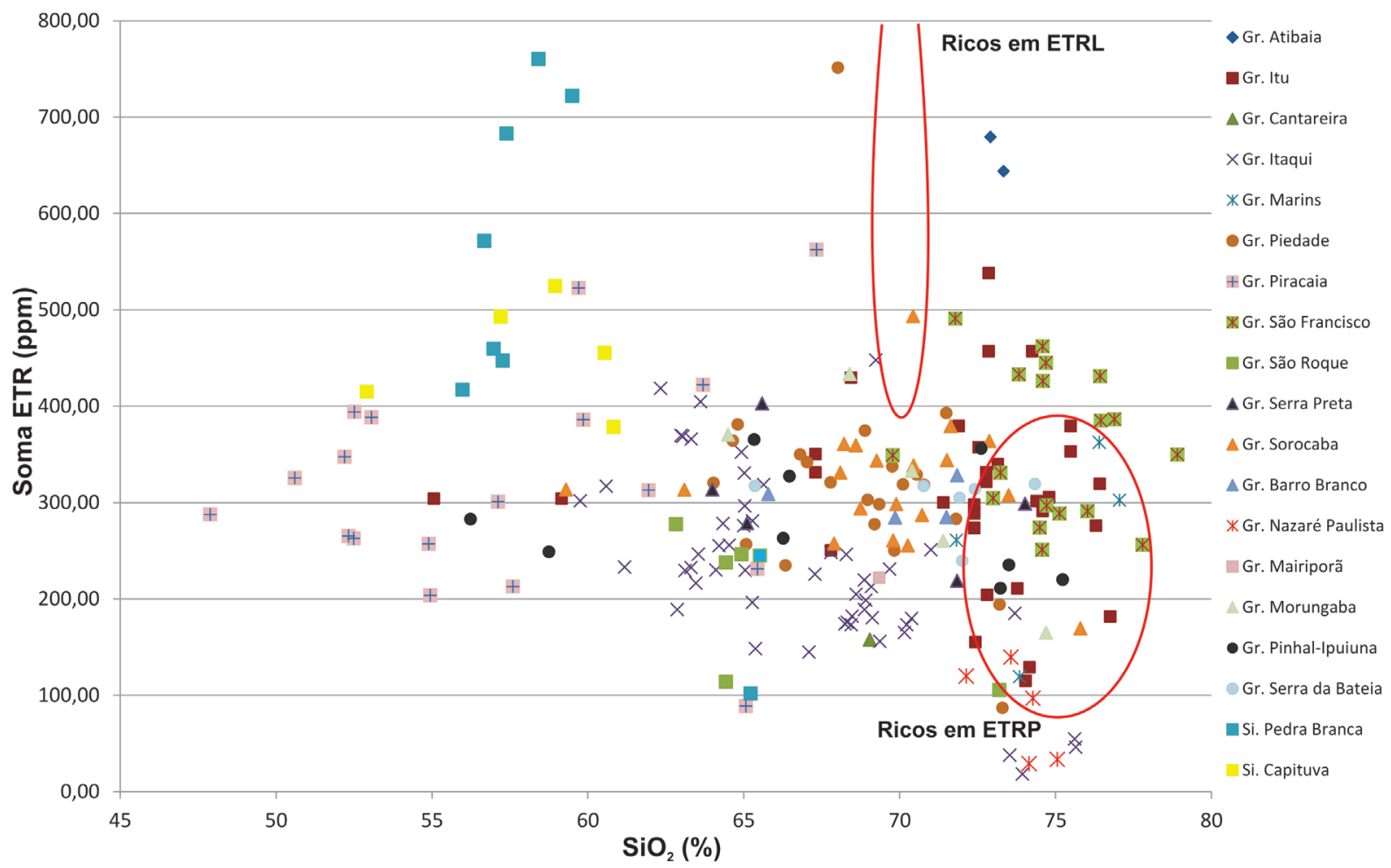

ETR: elementos terras raras; ETRL: elementos terras raras leves; ETRP: elementos terras raras pesados. Fonte: Sanematsu e Watanabe (2016).

Figura 3. Relação do conteúdo de sílica $\left(\mathrm{SiO}_{2}\right)$ com o conteúdo total de elementos terras raras e comparação com os campos delimitados por resultados químicos dos granitos geradores dos depósitos exógenos de elementos terras raras no Sudeste Asiático.

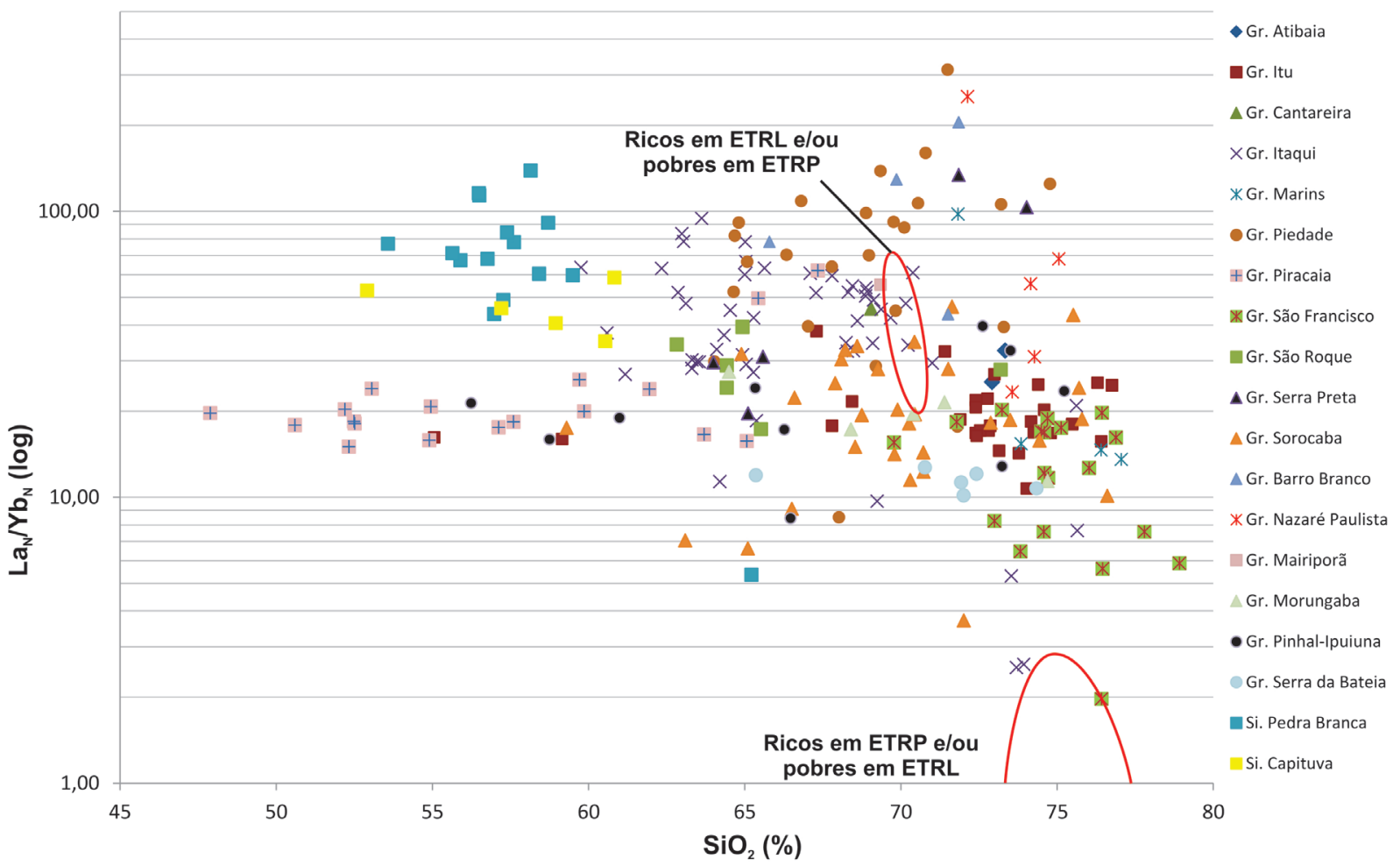

ETRL: elementos terras raras leves; ETRP: elementos terras raras pesados. Fonte: Sanematsu e Watanabe (2016).

Figura 4. Relação do conteúdo de sílica $\left(\mathrm{SiO}_{2}\right)$ com a razão $\mathrm{La}_{\mathrm{N}} / \mathrm{Yb}_{\mathrm{N}}$ (condrito de Sun e McDonough, 1989) e comparação com campos dos litotipos geradores dos depósitos exógenos de elementos terras raras na China. 
A relação $\mathrm{La}_{N} / \mathrm{Yb}_{\mathrm{N}}$ se mostrou o fator comparativo menos favorável para gênese de concentrações de ETRP tipo IAC. Os dados totais apresentam tendência de correlação positiva entre o aumento do conteúdo de ETR e o enriquecimento relativo de ETRL (Figura 5), além da inexistência de relações $\mathrm{La}_{\mathrm{N}} / \mathrm{Yb}_{\mathrm{N}}$ inferiores a 1, como em exemplares chineses geradores de jazidas. Essas características podem estar refletindo tanto diferenças próprias da química e da mineralogia dos granitos quanto distintos aspectos relativos à alteração hidrotermal (Watanabe et al., 2017).

Mesmo com as divergências da relação $\mathrm{La}_{\mathrm{N}} / \mathrm{Yb}_{\mathrm{N}}$, uma série de amostras apresenta conteúdos de totais de ETR com valores acima daqueles que definem o campo de geração de concentrações de ETRP (Figura 2), resultando, também, em maiores teores absolutos de ETRP. Nessa situação, uma vez que esse conteúdo de ETRP esteja contido em minerais propícios à abertura pelo ataque do processo de intemperismo, ainda seria possível o enriquecimento exógeno de ETRP adsorvidos em argilominerais, mesmo que as relações $\mathrm{La}_{\mathrm{N}} / \mathrm{Yb}_{\mathrm{N}}$ não sejam tão próximas àquelas dos corpos que originam esse modelo de mineralização. Deve ser considerado, também, que os ETRP se alojam, ainda que em menores quantidades, em minerais formadores de rocha (Cullers e Graf, 1984). Uma vez que a força iônica dos ETR na solução de transporte influencia na adsorção desses elementos em argilominerais (Guangzhi, 1996), quando em processos intempéricos de longa duração, a liberação lenta pode contribuir para essa adsorção por argilas neoformadas. Caberia então avaliar a capacidade de enriquecimento dos ETRP por essa ótica, a qual é distinta da visão de rápida liberação dos ETR de minerais (fluor)carbonáticos nos corpos graníticos mineralizados.

Nos maciços São Francisco, Itu, Sorocaba, Serra da Bateia, Pinhal-Ipuiuna, Marins e São Roque, determinadas fácies graníticas contam com redução da relação $\mathrm{La}_{\mathrm{N}} / \mathrm{Yb}_{\mathrm{N}}$ paralela ao incremento de $\mathrm{SiO}_{2}$ (Figura 4). Essa situação indica aumento relativo do conteúdo de ETRP em rochas fracionadas, o que pode estar associado à adição de ETR por ação de fluidos promotores de alteração magmática/hidrotermal (Bau e Dulski, 1995), situação essa que é favorável ao modelo de enriquecimento exógeno de ETR do tipo IAC, como apresentado anteriormente.

Os teores de $\mathrm{P}_{2} \mathrm{O}_{5}$ mostram tendência de diminuição acompanhando o aumento do grau de fracionamento magmático (Figura 6), com destaque para o conjunto de amostras com mais de $70 \%$ de $\mathrm{SiO}_{2}$ e menos de $0,1 \%$ de $\mathrm{P}_{2} \mathrm{O}_{5}$. Esses litotipos muito evoluídos e com indicativo de baixa presença de fosfatos de ETR são mais favoráveis ao modelo aqui tratado, dado que esses minerais fosfáticos mostram alta resistência ao intemperismo, impossibilitando a liberação

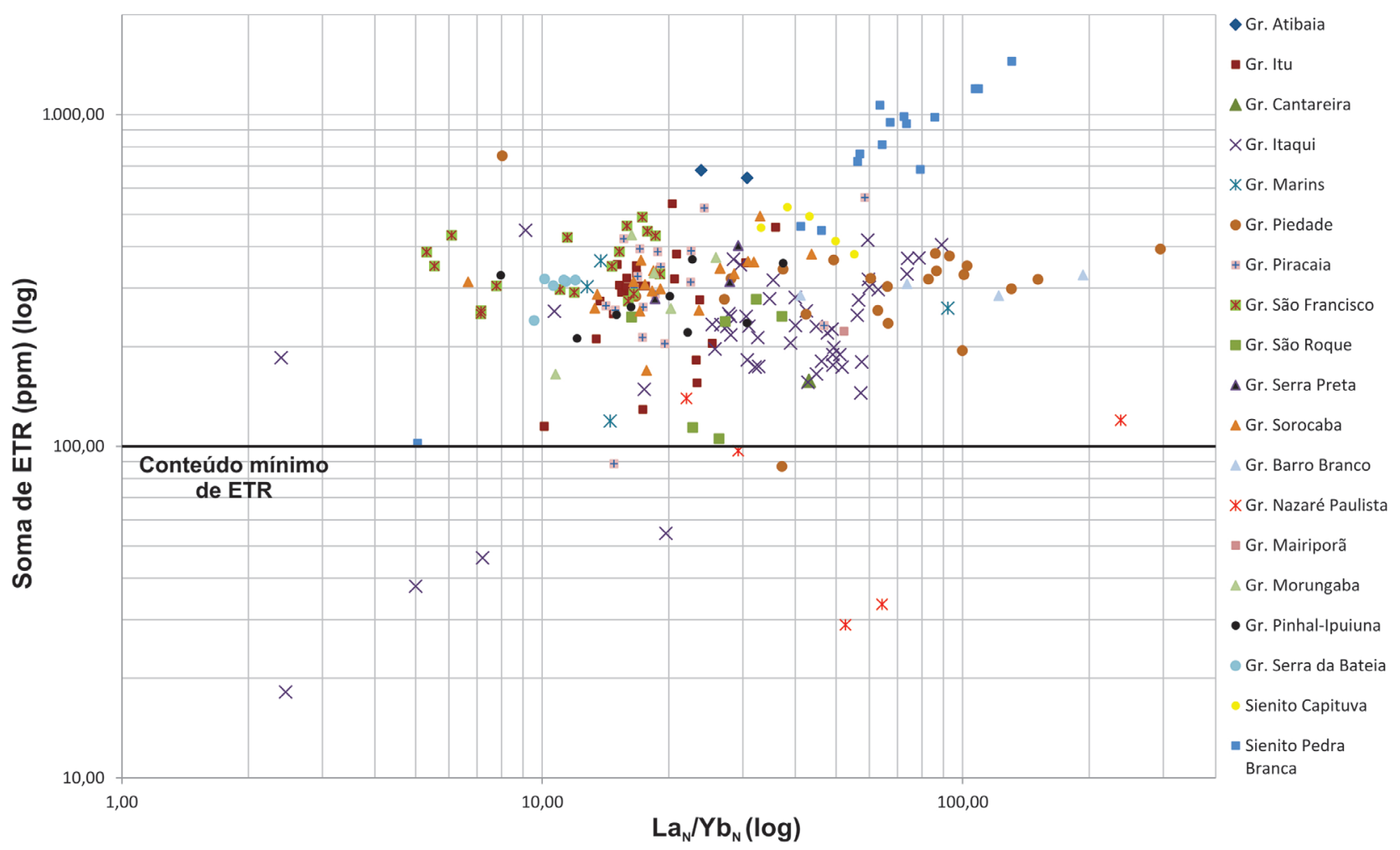

ETR: elementos terras raras.

Figura 5. Variação do conteúdo de elementos terras raras de acordo com a relação $\mathrm{La}_{\mathrm{N}} / \mathrm{Yb}_{\mathrm{N}}$ (condrito de $\mathrm{Sun}$ e McDonough, 1989) para os resultados químicos compilados. 
do conteúdo desses elementos para posterior adsorção por argilominerais neoformados (Sanematsu et al., 2015).

Os granitos Itu, São Francisco, Sorocaba, Serra da Bateia e Atibaia, todos tardi- ou pós-tectônicos (Leite et al., 2004), tiveram maior destaque na análise comparativa com os corpos geradores de mineralizações exógenas de ETR (Tabela 2). As referências bibliográficas compiladas indicam que esses corpos graníticos apresentam a biotita como mineral máfico predominante e titanita e allanita entre os minerais acessórios, com menor presença de hornblenda, mineralogia essa que é similar aos granitos geradores das jazidas de ETR tipo IAC (Sanematsu e Watanabe, 2016).

Em contrapartida, os levantamentos bibliográficos apontam que nos maciços sin-tectônicos há uma prevalência de

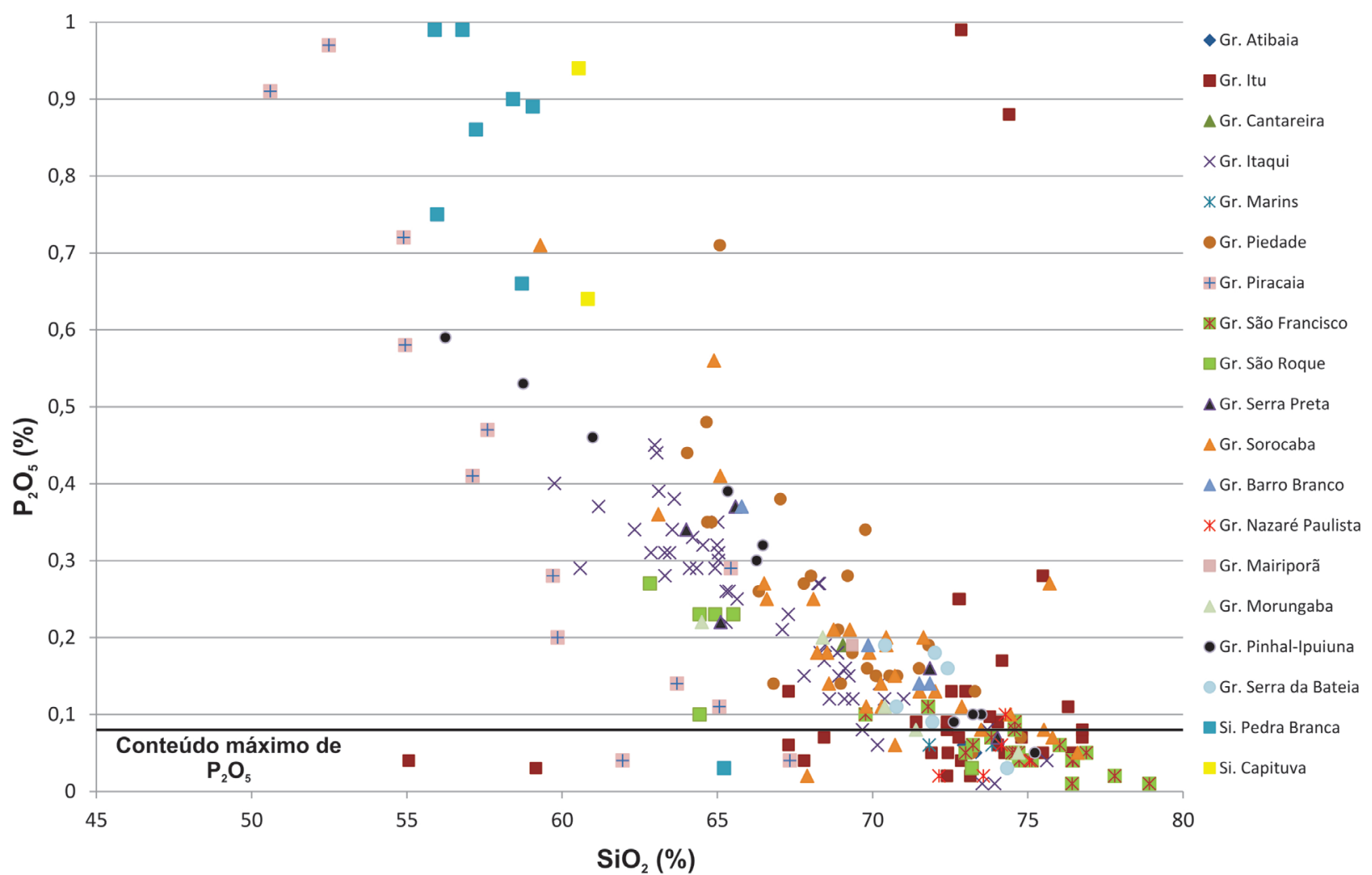

Figura 6. Relação entre o conteúdo de $\mathrm{SiO}_{2}$ e $\mathrm{P}_{2} \mathrm{O}_{5}$ nos corpos ígneos abordados e comparação com o limite superior de conteúdo de fosfato indicado por Sanematsu et al. (2015) para gênese do modelo de concentração exógena de elementos terras raras.

Tabela 2. Resumo dos aspectos básicos que conferem aos corpos graníticos selecionados a potencialidade prospectiva para geração de concentrações de elementos terras raras do tipo adsorvidos em argilominerais neoformados.

\begin{tabular}{|c|c|c|c|c|c|}
\hline Atributos & Itu & Sorocaba & São Francisco & Atibaia & Serra da Bateia \\
\hline Litotipos & \multicolumn{5}{|c|}{$\begin{array}{l}\text { Prevalência de biotita sienogranitos } \\
\end{array}$} \\
\hline $\mathrm{SiO}_{2}$ & \multirow{2}{*}{\multicolumn{5}{|c|}{$\begin{aligned} & >70 \% \\
& >4 \%\end{aligned}$}} \\
\hline $\mathrm{K}_{2} \mathrm{O}$ & & & & & \\
\hline Composição & \multicolumn{3}{|c|}{ Metaluminosa a peraluminosa } & Peraluminosa & Metaluminosa a \\
\hline $\mathrm{P}_{2} \mathrm{O}_{5}$ & \multicolumn{5}{|c|}{$<0,1 \%$} \\
\hline $\begin{array}{l}\text { Minerais originais } \\
\text { de ETR }\end{array}$ & \multicolumn{5}{|c|}{ Destaque para allanita, titanita e monazita } \\
\hline $\begin{array}{l}\text { Processos de } \\
\text { alteração }\end{array}$ & \multicolumn{5}{|c|}{ Greisenização é um processo comum a todos esses corpos } \\
\hline$\Sigma$ ETR & $>100$ ppm & $>150$ ppm & > 350 ppm & $>250$ ppm & $>200 \mathrm{ppm}$ \\
\hline$L a_{N} N \mathrm{Yb}_{N}$ & 10,13 a 35,94 & 5,31 a 19,05 & 1,97 a 20,17 & 23,9 a 30,73 & 9,57 a 12 \\
\hline
\end{tabular}

ETR: elementos terras raras. 
hornblenda como mineral máfico, com a biotita originada a partir desse anfibólio. Uma vez que a hornblenda aloja em sua estrutura maiores conteúdos de ETR do que a biotita (Gromet e Silver, 1983), a presença desse anfibólio em larga escala seria contraproducente ao modelo de concentração de ETR tipo IAC, já que, quando comparada à biotita, abriga uma fração maior desses elementos e também apresenta uma disponibilização mais lenta de seu conteúdo quando comparada aos (fluor)carbonatos de ETR.

Tratando os processos de alteração, os batólitos São Francisco e Sorocaba apresentam greisenização, responsável por ocorrências de wolframita, cassiterita, galena, pirita e calcopirita nesses corpos (Godoy, 1989). No Batólito Agudos Grandes, que abriga o Maciço Serra da Bateia, é descrita a alteração por greisenização, sem maiores considerações sobre esse processo (Leite et al., 2007). O Batólito Itu, por sua vez, é mineralizado em cassiterita originada em processo de greisenização (Galembeck, 1997). Esses corpos graníticos não dispõem de caracterizações das mineralogias portadoras de ETR. Porém, os conteúdos totais desses elementos, a presença de allanita e titanita e os indícios de sobreposição de processos de alteração magmática/hidrotermal são compatíveis com a formação de minerais (fluor)carbonáticos de ETR (Bao e Zhao, 2008; Sanematsu e Watanabe, 2016), conferindo potencial prospectivo a esses corpos segundo o modelo de mineralização de ETR pesquisado.

A fácies de álcali-quartzo sienito do Maciço Piracaia apresenta teores médios compilados de $\mathrm{SiO}_{2}$ e ETR, respectivamente, de 63,53\% e 542,49 ppm, com relação $\mathrm{La}_{\mathrm{N}} / \mathrm{Yb}_{\mathrm{N}}$ variando de 25,74 a 62,07 . Sua origem deu-se em magmatismo shoshonítico com fonte na fusão de protólito mantélico rico em elementos incompatíveis e com anomalia positiva em Gd (Wernick et al., 1997), seguido de processos de alteração magmática e hidrotermal (Ragatky, 1998). Tomando como base o expressivo conteúdo total de ETR, a determinação das mineralogias portadoras desses elementos auxiliaria a avaliação de sua capacidade para gênese do modelo metalogenético aqui tratado, mesmo que o corpo não tenha se firmado entre aqueles de maior potencialidade para gerar esse tipo de concentração de ETR.

No Sienito Pedra Branca, a titanita e a apatita, este representado pelo alto conteúdo de $\mathrm{P}_{2} \mathrm{O}_{5}$ (Figura 6), são responsáveis por alojar grande parte do conteúdo dos ETR (Carvalho e Janasi, 2012). Dado que ambos os minerais são resistentes ao intemperismo, no primeiro momento esse corpo teria pouco potencial para esse tipo de concentração exógena de ETR (Bao e Zhao, 2008). Porém, cabe salientar que a comparação de dados químicos aqui compilados se embasa em corpos cujas litologias são graníticas, interferindo na compatibilidade dos resultados químicos dos corpos sieníticos Capituva e Pedra Branca com os campos delimitados nos gráficos apresentados por Sanematsu e Watanabe (2016). Nesse caso, a análise prospectiva nesses corpos sieníticos pode se embasar na mineralização exógena de ETR do tipo IAC desenvolvida pelo intemperismo de zonas skarníticas de sienitos em Madagascar (Harmer e Nex, 2016). Então, os conteúdos totais de ETR (Figura 3) nesses dois corpos sieníticos, acompanhados dos processos de alteração pela intrusão do Maciço Alcalino Poços de Caldas e pelo intemperismo ali atuante (Janasi, 1992), compõem um conjunto de atributos que poderiam sustentar a avaliação dos maciços Pedra Branca e Capituva para presença de mineralizações de ETR adsorvidos em argilominerais. Nesse caso, os principais fatores a serem considerados serão os produtos e a efetividade das substituições mineralógicas impostos pela alteração resultante da intrusão do Maciço Poços de Caldas.

\section{Potencial de presença de perfis de intemperismo nos corpos selecionados}

As informações de aerogamaespectrometria (Figura 7) foram aplicadas aos cinco corpos (Itu, São Francisco, Sorocaba, Atibaia e Serra da Bateia) definidos na etapa anterior de prospecção como possíveis geradores de concentrações exógenas de ETR do tipo IAC. Assim, com base na razão $\mathrm{Th} / \mathrm{K}$, obteve-se um indicador da presença de perfis de intemperismo nas extensões desses corpos, o que poderia gerar condições de mobilidade dos ETR seguidas de enriquecimento desses elementos no horizonte saprolítico, corroborando, então, a instalação do processo mineralizador sobre esses cinco corpos graníticos.

Por se tratarem de corpos graníticos com alta diferenciação, cujos teores de $\mathrm{K}_{2} \mathrm{O}$ são superiores a $4 \%$, as extensões dos corpos graníticos portando baixa relação $\mathrm{Th} / \mathrm{K}$ refletem a presença da rocha aflorante ou subaflorante, enquanto o oposto estaria relacionado ao enriquecimento, nos solos, de minerais portadores de The resistentes ao intemperismo (Ulbrich et al., 2009). Essa situação de alta relação $\mathrm{Th} / \mathrm{K}$, indicando valores maiores para o numerador em relação ao denominador, fez-se presente nesses cinco corpos avaliados (Figura 7), o que é destacado pelas cores mais quentes.

A partir das características dos domínios geomorfológicos em que se colocam os granitos apresentados na Figura 7 e dos indicadores aerogeofísicos, indica-se o potencial de instalação e preservação de perfis de intemperismo portando horizonte saprolítico, originados por avançado grau de alteração exógena típica de ambiente tropical (Wilford et al., 1997). Como são diversos os fatores que implicam na capacidade de adsorção dos ETR em argilominerais neoformados (Guangzhi, 1996), a aferição do enriquecimento desses elementos somente pode ser feita com a avaliação direta dos saprolitos graníticos. Considerando a existência do saprolito, com neoformação de argilominerais, ter-se-ia o primeiro indicativo para geração das condições de ocorrer a adsorção dos ETR, onde se considera que tenha havido a possibilidade de liberação dos ETR de suas mineralogias 
originais e mobilização no perfil de intemperismo. Então, a definição, por si só, de indícios que apontem o potencial de presença de perfil de intemperismo contendo horizonte saprolítico nos domínios desses granitos é condição suficiente para, com base em indicadores indiretos, determinar a existência de potencial prospectivo para o modelo de concentração de ETR do tipo IAC.

As extensões e as continuidades das porções potenciais à presença desses perfis de intemperismo variam entre esses corpos selecionados, o que é indicado pelas variações da relação Th/K. Nesse caso, os granitos São Francisco, Itu e Serra da Bateia merecem ser destacados pela larga cobertura de extensões com altos valores para essa relação, sugerindo extensa cobertura intempérica preservada de erosão. Já nos granitos Sorocaba e Atibaia as altas relações $\mathrm{Th} / \mathrm{K}$ se dão em áreas de menor expressão, o que pode sugerir, em relação aos outros três corpos analisados, menor potencial prospectivo, mas não permite descartar completamente o potencial desses corpos para concentração exógena de ETR do tipo IAC.

\section{CONCLUSÕES}

Os resultados obtidos apontam para o potencial de ocorrências minerais de ETR abordando um modelo de gênese pouco aplicado no Brasil, nesse caso, com enriquecimento desses elementos pela adsorção em argilominerais neorformados, sendo identificadas em uma região do país cujos conhecimentos geológicos se encontram em fase avançada de maturidade. Essa situação é particularmente interessante quando se considera o potencial de concentração de ETRP, com grande perspectiva de expansão de consumo e baixos volumes de recursos e reservas no país.

Os granitos Itu, São Francisco, Sorocaba, Atibaia e Serra da Bateia apresentaram aspectos comparáveis àqueles granitos

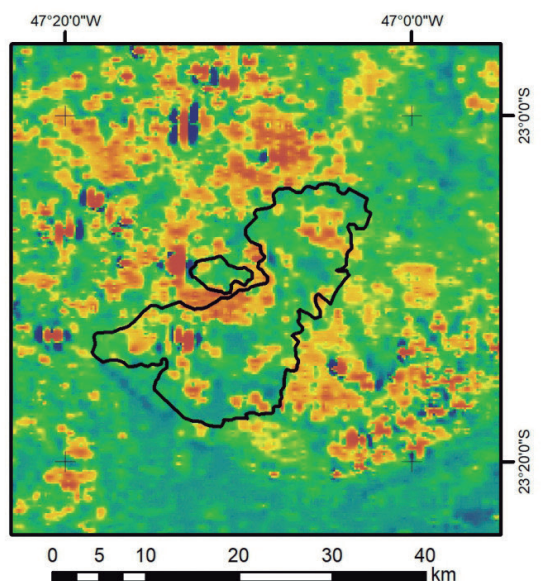

Batólito Itu

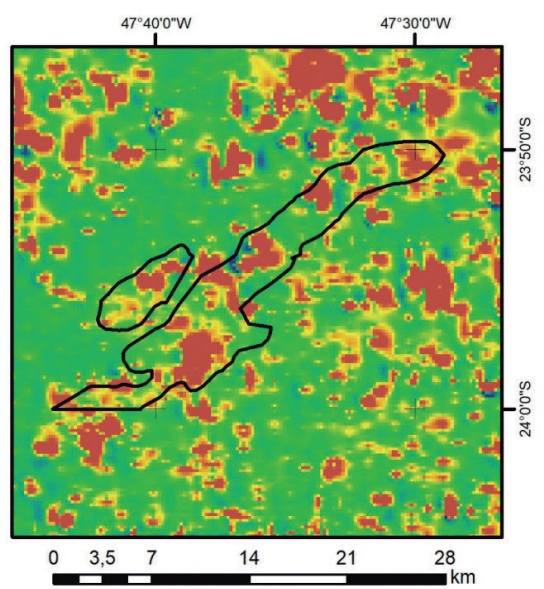

Maciço Granítico Serra da Bateia

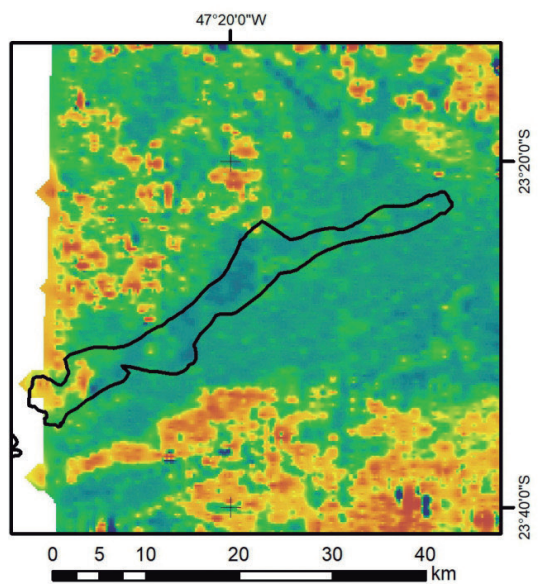

Batólito Sorocaba

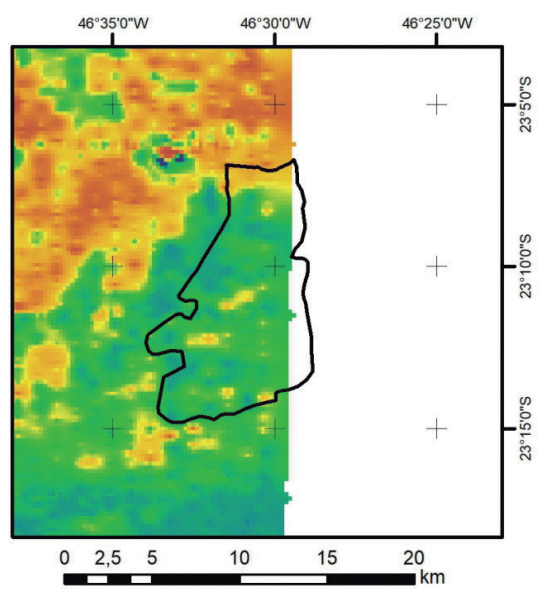

Plúton Atibaia

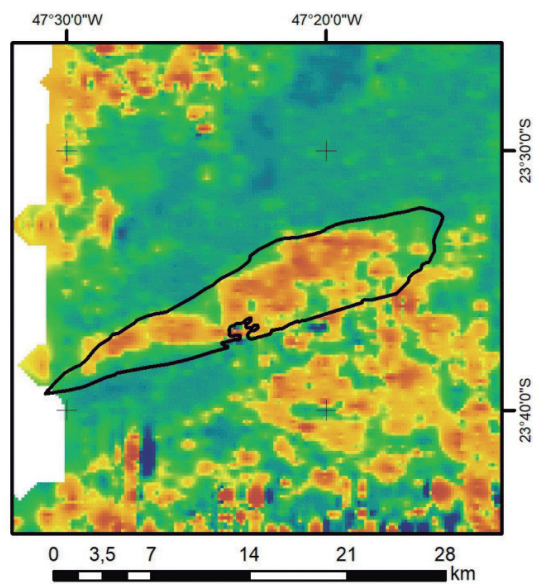

Batólito São Francisco
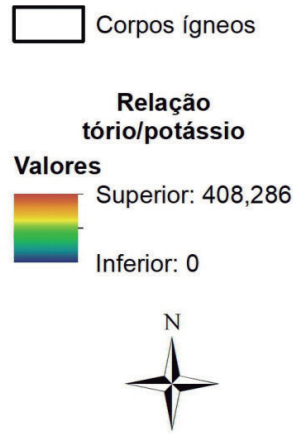

Figura 7. Relação Th/K na extensão dos corpos graníticos de maior potencial para geração de concentrações exógenas de elementos terras raras adsorvidos em argilas. 
geradores de concentrações exógenas de ETR adsorvidos em argilominerais, o que é evidenciado pela soma dos aspectos químicos com as características geológicas e de minerais acessórios (Bao e Zhao, 2008; Sanematsu et al., 2015; Sanematsu e Watanabe, 2016). Esses granitos tardi a póstectônicos são originados por magmatismos calcioalcalinos (de alto K) e alcalinos, com fontes crustal e mantélica e assinatura de manto enriquecido, o que contribui para maiores conteúdos de elementos incompatíveis, entre os quais os ETR. Soma-se ainda a sobreposição de processos de alteração hidrotermal nesses maciços, destacando a greisenização, o que pode ter contribuído para a gênese de minerais (fluor) carbonáticos de ETR, muito susceptíveis ao intemperismo, e também para o enriquecimento de ETRP nessas rochas. Além dessas características, ressaltam-se os indicativos de instalação de processo de intemperismo tropical seguidos da preservação de perfis possivelmente detentores de horizonte saprolítico, condições essas que são necessárias para promover a liberação do conteúdo de ETR das mineralogias originais, a mobilização e o enriquecimento desses elementos por adsorção em argilominerais neoformados.

Em contrapartida, a análise comparativa aplicada indica que os corpos ígneos sin-colisionais teriam baixa capacidade prospectiva para gerarem depósitos de ETR do tipo IAC, o que se deve a uma sucessão de características que não seriam condizentes com a possibilidade de gênese de minerais de ETR muito susceptíveis ao intemperismo, além de baixo conteúdo relativo de ETRP, mais interessantes a esse modelo de enriquecimento exógeno por adsorção em argilominerais neoformados. O mesmo aplica-se àqueles corpos com forte contribuição de fontes metassedimentares (Maciço Nazaré Paulista), que apresentaram baixo conteúdo total de ETR e alta relação $\mathrm{La}_{\mathrm{N}} / \mathrm{Yb}_{\mathrm{N}}$, onde também há menores condições de geração dos minerais de ETR de interesse ao modelo.

Uma vez que esses cinco corpos selecionados exibiram indícios litológicos, químicos e intempéricos potenciais ao enriquecimento dos ETR por adsorção em argilominerais neoformados, entende-se haver um conjunto de informações que sustentam a abordagem prospectiva direta desses corpos graníticos e respectivos perfis de intemperismo para avaliações pertinentes ao estudo desse modelo de mineralização exógena. Da mesma forma, os resultados obtidos podem ser entendidos como uma introdução ao potencial brasileiro para prospecção mineral desse tipo de depósito de ETR.

\section{AGRADECIMENTOS}

Ao Conselho Nacional de Desenvolvimento Científico e Tecnológico (CNPq) pelo fomento da pesquisa (Processo n.141.449/2017-9) e aos revisores pela contribuição nas melhorias do trabalho.

\section{REFERÊNCIAS}

Andrade, F. R. D. (1993). Complexo Granitoide São Roque: petrografia, litoquímica e tipologia de zircão. Dissertação (Mestrado). Rio Claro: Instituto de Geociências e Ciências Exatas - UNESP.

Artur, A. C. (1988). Evolução Policiclica da Infra-Estrutura da Porção Sul do Estado de Minas Gerais e Regiões Adjacentes do Estado de São Paulo. Tese (Doutorado). São Paulo: Instituto de Geociências - USP. http://doi. org/10.11606/T.44.1988.tde-19062015-145055

Bao, Z., Zhao, Z. (2008). Geochemistry of mineralization with exchangeable REY in the weathering crusts of granitic rocks in South China. Ore Geology Reviews, 33, 519-535. https://doi.org/10.1016/j.oregeorev.2007.03.005

Bau, M., Dulski, P. (1995). Comparative study of yttrium and rare-earth element behaviours in fluorine-rich hydrothermal fluids. Contributions to Mineralogy and Petrology, 119(23), 213-223. https://doi.org/10.1007/BF00307282

Brito Neves, B. B., Fuck, R. A. (2014). The basement of South-American Platform: half Gondwana + half Laurentia. Precambrian Research, 244, 75-86. http://doi.org/10.1016/j. precamres.2013.09.020

Campos Neto, M. C. (2000). Orogenic systems from Southwestern Gondwana: an approach to Brasiliano-PanAfrican cycle and orogenic collage in Southeastern Brazil. In: U. G. Cordani, E. J. Milani, A. Thomaz Filho, D. A. Campos (Eds.), Tectonic evolution of South America (335-365). Rio de Janeiro: XXXI Congresso Internacional de Geologia.

Campos Neto, M. C., Basei, M. A. S., Vlach, S. R. F., Caby, R., Szabó, G. A. J., Vasconcelos, P. (2004). Migração de orógenos e superposição de orogêneses: um esboço da Colagem Brasiliana no Sul do Cráton do São Francisco, SE-Brasil. Geologia USP. Série Científica, 4(1), 13-40. http://doi.org/10.5327/S1519-874x2004000100002

Carvalho, B. B., Janasi, V. A. (2012). Crystallization conditions and controls on trace element residence in the main minerals from the Pedra Branca Syenite, Brazil: An electron microprobe and LA-ICPMS study. Lithos, 153, 208-223. http://doi. org/10.1016/j.lithos.2012.05.003

Carvalho, B. B.Carvalho, B. B, Janasi, V. de A., Henrique-Pinto, R. (2014). Geochemical and $\mathrm{Sr}-\mathrm{Nd}-\mathrm{Pb}$ isotope constraints on the petrogenesis of the K-rich Pedra Branca Syenite: implications for the Neoproterozoic post-collisional magmatism in SE Brazil. Lithos, 205, 39-59. https://doi.org/10.1016/j.lithos.2014.06.016 
Cullers, R. L., Graf, J. L. (1984). Rare-earth elements in igneous rocks of the continental crust: intermediate and silicic rocks-ore petrogenesis. In: P. Henderson (Ed.), Rare Earth Element Geochemistry (1, 275-316). Amsterdã: Elsevier.

Duffles, P. A., Trouw, R. A. J., Mendes, J. C., Gerdes, A. (2013). Marins Granite (MG/SP): petrography, geochemistry, geochronology, and geotectonic setting. Brazilian Journal of Geology, 43(3), 487-500. http://doi.org/10.5327/ Z2317-48892013000300006

Ferreira, C. J. (1996). Geoquímica e análise da deformação do complexo Itaqui, SP: Evolução de granitos cálcio-alcalinos poli-intrusivos. Tese (Doutorado). Rio Claro: Instituto de Geociências e Ciências Exatas - UNESP.

Galembeck, T. M. B. (1997). O complexo múltiplo centrado e plurisserial Itu, SP. Tese (Doutorado). Rio Claro: Instituto de Geociências e Ciências Exatas - UNESP.

Godoy, A. M. (1989). Caracterização Faciológica, Petrográfica e Geoquímica dos Maciços Sorocaba e São Francisco, SP. Tese (Doutorado). São Paulo: Instituto de Geociências - USP. http://doi.org/10.11606/T.44.1989. tde-19062015-150133

Godoy, A. M., Hackspacher, P. C., Oliveira, M. A. F. de, Araujo, L. M. B. de (2010). Evolução geológica dos batólitos granitóides neoproterozóicos do sudeste do Estado de São Paulo. Revista Brasileira de Geociências, 29, 171-185.

Godoy, A. M., Hackspacher, P. C., Oliveira, M. A. F. de, Gomes, A. B. (1999). Geoquímica dos Maciços Granitóides Ibiúna e Piedade na Folha Sorocaba - SP. Geociências, 18, 157-178.

Gromet, L. P., Silver, L. T. (1983). Rare earth element distributions among minerals in a granodiorite and their petrogenetic implications. Geochimica et Cosmochimica Acta, 47, 925-939. https://doi.org/10.1016/0016-7037(83)90158-8

Guangzhi, T. (1996). Low temperature geochemistry. Pequim: China Science Press.

Haddad, R. C. (1995). O Batólito Granitóide Pinhal-Ipuiuna (SP-MG): um exemplo do magmatismo cálcio-alcalino potássico neoproterozóico no sudeste brasileiro. Tese (Doutorado). São Paulo: Instituto de Geociências - USP. http://doi.org/10.11606/T.44.1995.tde-03062015-134235

Harmer, R. E., Nex, P. A. M. (2016). Rare earth deposits of Africa. Episodes, 39(2), 381. http://doi.org/10.18814/ epiiugs/2016/v39i2/95784
Heilbron, M., Pedrosa-Soares, A. C., Silva, L. C., Campos Neto, M. C., Trouw, R. A. J. (2004). Província Mantiqueira. In: V. Mantesso Neto, A. Bartorelli, C. D. R. Carneiro, B. B. Brito Neves (Eds.), Geologia do Continente Sul-Americano (1-13). Rio de Janeiro: Beca.

Ishihara, S., Hua, R., Hoshino, M., Murakami, H. (2008). REE abundance and REE minerals in granitic rocks in the Nanling range, Jiangxi Province, Southern China, and generation of the REE-rich weathered crust deposits. Resource Geology, 58, 355-372. https://doi.org/10.1111/j.1751-3928.2008.00070.x

Janasi, V. A. (1992). Rochas sieníticas e mangeríticocharnoquiticas Neoproterozóicas da região entre Caldas e Campestre, MG: Aspectos Petrológicos. Tese (Doutorado). São Paulo: Instituto de Geociências - USP. http://doi. org/10.11606/T.44.1992.tde-28092012-155830

Janasi, V. A.Janasi, V. A. (1993). Petrogenesis and tectonic setting of the neoproterozoic Capituva K-syenite, SW Minas Gerais. Revista Brasileira de Geociencias, 23(2), 129-138.

Janasi, V. A. (1999). Petrogênese de granitos crustais na Nappe de Empurrão Socorro-Guaxupé (SP$M G)$ : uma contribuição da geoquímica elemental e isotópica. Tese (Livre-Docência). São Paulo: Instituto de Geociências - USP. http://doi.org/10.11606/T.44.2013. tde-04062013-164954

Janasi, V. A. (2002). Elemental and Sr-Nd isotope geochemistry of two Neoproterozoic mangerite suites in SE Brazil: implications for the origin of the mangerite-charnockitegranite series. Precambrian Research, 119, 301-327. http:// dx.doi.org/10.1016/S0301-9268(02)00127-4

Janasi, V. A., Ulbrich, H. H. G. J. (1991). Late Proterozoic granitoid magmatism in the State of São Paulo, southeastern Brazil. Precambrian Research, 51, 351-374. https://doi. org/10.1016/0301-9268(91)90108-M

Janasi, V. A., Vlach, S. R. F. (1997). Sr and Nd isotope systematics of the Capituva and Pedra Branca syenitic massifs (SW Minas Gerais, Brazil): petrogenesis and inference on Neoproterozoic lithospheric mantle reservoirs. I Simpósio Sul Americano de Geologia Isotópica, 143-146. Campos de Jordão: FAPESP/CNPq/CPRM.

Janasi, V. A., Vlach, S. R. F., Campos Neto, M. C., Ulbrich, H. H. G. J. (2009). Associated A-Type subalkaline and high-K calc-alkaline granites in the Itu Granite Province, southeastern Brazil: petrological and tectonic significance. The Canadian Mineralogist, 47, 1505-1526. http://doi. org/10.3749/canmin.47.6.1505 
Leite, C. A. S., Perrota, M. M., Silva, L. C., Silva, M. A., Heineck, C. A., Salvador, E. D., Vieira, V. C., Lopes, R. C., Silva, M. G. M., Drumond, J. B. V., Malouf, R. F., Lacerda Filho, J. V., Valente, C. R., Gomes, S. D., Sachs, L. L. B., Oliveira, I. W. B., Ramgrab, G. E., Netto, C., Junqueira, P. A., Paes, V. J. C. (2004). Folha SF.23 - Rio de Janeiro. In: C. Schobbenhaus, J. H. Gonçalves, J. O. S. Santos, M. B. Abram, R. Leão Neto, G. M. M. Matos, R. M., Vidotti, M. A. B., Ramos, J. D. A., Jesus (Eds.), Carta geológica do Brasil ao Milionésimo, SIG. Brasília: CPRM.

Leite, R. J., Janasi, V. A., Creaser, R. A., Heaman, L. M. (2007). The late- to post-orogenic transition in the Apiai Domain, SE Brazil: constraints from the petrogenesis of the Neoproterozoic Agudos Grandes Granite Batholith. Journal of South American Earth Sciences, 23, 213-235. http://dx.doi.org/10.1016/j.jsames.2006.09.003

Leite, R. J., Janasi, V. A., Martins, L. (2006). Contamination in mafic mineral-rich calc-alkaline granites: a geochemical and Sr-Nd isotope study of the Neoproterozoic Piedade Granite, SE Brazil. Anais da Academia Brasileira de Ciências, 78, 345-371. http://dx.doi.org/10.1590/ S0001-37652006000200013

Linnen, R. L., Samson, I. M., Williams-Jones, A. E., Chakhmouradian, A. R. (2014). Geochemistry of the rareearth element, $\mathrm{Nb}, \mathrm{Ta}, \mathrm{Hf}$, and $\mathrm{Zr}$ deposits. In: S. D. Scott (Ed.), Treatise on geochemistry - Geochemistry of mineral deposits (13, 543-568). $2^{\mathrm{a}}$ ed. Oxford: Elsevier-Pergamon. http://doi.org/10.1016/B978-0-08-095975-7.01124-4

Mariano, A. N., Mariano, A. Jr. (2012). Rare earth mining and exploration in North America. Elements, 8, 369-376. https://doi.org/10.2113/gselements.8.5.369

Marini, O. J., Botelho, N. F., Rossi, P. (1992). Elementos terras raras em granitóides da Província Estanífera de Goiás. Revista Brasileira de Geociências, 22, 61-72.

Martins, L. (2005). Geração e migração de magmas graníticos na crosta continental: estudos de detalhe em granitos e migmatitos da região de Nazaré Paulista $(S P)$. Tese (Doutorado). São Paulo: Instituto de Geociências - USP. http://doi.org/10.11606/T.44.2006. tde-19042007-155618

Martins, L., Vlach, S. R. F., Janasi, V. A. (2009). Reaction microtextures of monazite: Correlation between chemical and age domains in the Nazaré Paulista migmatite, SE Brazil. Chemical Geology, 261, 271-285. https://doi.org/10.1016/j. chemgeo.2008.09.020
Melhem, M. M. (1995). Geologia e petrografia das rochas granitóides do Maciço Atibaia e adjacências, SP. Dissertação (Mestrado). São Paulo: Instituto de Geociências - USP. http://doi.org/10.11606/D.44.1995.tde-06102015-114844

Nesbitt, H. W. (1979) Mobility and fractionation of rare earth elements during weathering of a granodiorite. Nature, 279, 206-210. https://doi.org/10.1038/279206a0

Pereira, G. S. (2013). O significado dos enclaves microgranulares félsicos na evolução de magmas graníticos: petrologia dos enclaves do Granito Salto, Batólito Itu. Dissertação (Mestrado). São Paulo: Instituto de Geociências USP. http://doi.org/10.11606/D.44.2013.tde-13112013-151042

Pereira, R. M., Ávila, C. A., Moura, C. A. V., Roig, H. L. (2001). Geologia e geoquímica do Granito Medanha e do Granitóide Marins e idade ${ }^{207} \mathrm{~Pb} /{ }^{206} \mathrm{~Pb}$ do Granito Medanha, Faixa Ribeira, São Paulo. Geociências, 20(1), 46-60.

Prazeres Filho, H. J., Harara, O. M., Basei, M. A. S., Passarelli, C. R., Siga Jr., O. (2003). Litoquímica, geocronologia $\mathrm{U}-\mathrm{Pb}$ e geologia isotópica ( $\mathrm{Sr}-\mathrm{Nd}-\mathrm{Pb}$ ) das rochas graníticas dos batólitos Cunhaporanga e Três Córregos na porção sul do Cinturão Ribeira, Estado do Paraná. Geologia USP. Série Científica, 3, 51-70. http://dx.doi.org/10.5327/ S1519-874X2003000100005

RADAMBRASIL. (1983). Ministérios de Minas e Energia. Levantamento dos recursos naturais - Folhas SF 23/24, Rio de Janeiro/Vitória. Rio de Janeiro: DNPM.

Ragatky, D. (1998). Contribuição à Geoquímica e Geocronologia do Domínio São Roque e da Nappe de Empurrão Socorro - Guaxupé, na Região de Igaratá e Piracaia, SP. Tese (Doutorado). São Paulo: Instituto de Geociências - USP.

Sanematsu, K., Kon, Y., Imai, A. (2015). Influence of phosphate on mobility and adsorption of REEs during weathering of granites in Thailand. Asian Earth Sciences, 111, 14-30. https://doi.org/10.1016/j.jseaes.2015.05.018

Sanematsu, K., Kon, Y., Imai, A., Watanabe, K., Watanabe, Y. (2013). Geochemical and mineralogical characteristics of ion-adsorption type REE mineralization in Phuket, Thailand. Mineralium Deposita, 48, 437-451. http://dx.doi.org/10.1007/ s00126-011-0380-5

Sanematsu, K., Watanabe, Y. (2016). Characteristics and genesis of ion adsorption-type rare earth elements deposits. In: P. L. Verplanck, M. W. Hitzman (Eds.), Reviews in Economic Geology $(18,55-79)$. Broomfield: Society of Economic Geologists. 
Santoro, E. (1998). Evolução geológica do Pré-Cambriano da região de Santo Antônio do Pinhal, SP: importância tectônica das zonas de cisalhamento. Tese (Doutorado). São Paulo: Instituto de Geociências - USP. https://doi. org/10.11606/T.44.1998.tde-28102015-093117

Sun, S. S., McDonough, W. F. (1989) Chemical and isotopic system atics of oceanic basalts: implications for mantle composition and processes. In: A. D., Saunders, M. J., Norry (Eds.), Magmatism in the Ocean Basins (42, 313345). Londres: The Geological Society.

Töpfner, C. (1996). Brasiliano-Granitoide in den Bundesstaaten São Paulo and Minas Gerais, Brasilien - eine vergleichende Studie. In: C. Töpfner (Ed.), Münchner Geologische (17, 1-258). Alemanha: Instituts für Allgemeine und Angewandte Geologie.

Tupinambá, M., Heilbron, M., Valeriano, C., Porto Júnior, R., Dios, F. B., Machado, N., Silva, L. G. E., Almeida, J. (2012). Juvenile contribution of the Neoproterozoic Rio Negro Magmatic Arc (Ribeira Belt, Brazil): implications for western Gondwana amalgamation. Gondwana Research, 21, 422-438. https://doi.org/10.1016/j.gr.2011.05.012

Ulbrich, H. H. G. J., Ulbrich, M. N. C., Ferreira, F. J. F., Alves, L. S., Guimarães, G. B., Fuchting, A. (2009). Levantamentos gamaespectrométricos em granitos diferenciados. I: Revisão da metodologia e do comportamento geoquímico dos elementos K, Th e U. Geologia USP. Série Cientifica, 9(1), 35-53. http://dx.doi.org/10.5327/Z1519-874X2009000100003

Vlach, S. R. F., Janasi, V. A., Vasconcellos, A. C. B. C. (1991). O magmatismo granitoide tardi- a pós-orogênico de idade brasiliana do Estado de São Paulo. Boletim do Instituto de Geociências da USP, 9, 99-101. https://doi.org/10.11606/ issn.2317-8078.v0i9p99-101
Watanabe, Y., Kon, Y., Echigo, T., Kamei, A. (2017). Differential fractionation of rare earth elements in oxidized and reduced granitic rocks: implication for heavy rare earth enriched ion adsorption mineralization. Resource Geology, 67(1), 35-52. https://doi.org/10.1111/ rge.12119

Wernick, E. (2000). Arc-related rapakivi granites from the Ribeira Fold Belt, SE Brazil. Revista Brasileira de Geociências, 30(1), 20-24.

Wernick, E., Artur, A. C., Hörmann, P. K., Weber-Diefenbach, K., Fahl, C. (1997). O magmatismo alcalino potássico Piracaia, SP (SE Brasil): aspectos composicionais e evolutivos. Revista Brasileira de Geociências, 27(1), 53-66.

Wernick, E., Galembeck, T. M. B. (1986). Caracterização do plutonismo granitoide do Ciclo Brasiliano no Estado de São Paulo através do método de tipologia de zircão. XXXIV Congresso Brasileiro de Geologia, 3, 1369-1382. Goiânia: SBG.

Wilford, J. R., Bierwirth, P. N., Craig, M. A. (1997). Application of airborne gamma-ray spectrometry in soil/ regolith mapping and applied geomorphology. AGSO Journal of Australian Geology \& Geophysics, 17(2), 201-216.

Wu, C., Dianhao, H., Zhongxun, G. (1990). REE geochemistry in the weathered crust of granites, Longnan area, Jiangxi Province. Acta Geologica Sinica, 3(2), 193-209. https://doi. org/10.1111/j.1755-6724.1990.mp3002006.x

Zielenski, M. (1993). Petrologie und Zirkontypologie der Granite von Itu und São Roque, Staat São Paulo (Brasilien). M.Sc. Thesis. Kiel: Mineralogisch-Petrographisches Institut und Museum - Christian-Albrecht Universität. 